\title{
La mujer en La moral de Don Quixote de Pedro Gatell, marino y cirujano ilustrado
}

JOSÉ LUIS PESET

IH-CCHS-CSIC

«La guerra de Troya no tuvo otro agente que una manzana»

P. Gatell, La moral de don Quixote, I, 75

\section{UN CIRUJANO ILUSTRADO}

Es Pedro Gatell un escritor poco conocido y, lo que es peor, se trata a mi entender de un mal escritor y un pesado moralista (Larriba 2005). Mal escrito está el libro que ahora comento, con prisas, repeticiones, equivocaciones de imprenta..., a veces faltan o parecen faltar palabras, también páginas, con errores de numeración, tal vez haya galicismos, que pueden señalar sus fuentes francesas (Gatell 1792-1793). Parece el autor tener prisa en la edición, en efecto le quedaba poco tiempo, como a Alonso Quijano el bueno. Sermoneante y conservador, llena el autor sus páginas de elogios al rey — no olvida a la reina- y a la religión, si bien añade con cuidado los dedicados a la patria. Extraña en un personaje con la excelente formación de los cirujanos militares, que tanto batalló por mejorar la ciencia y el periodismo entre nosotros. La revolución francesa ha trastornado a muchos ilustrados españoles.

De todas formas, conserva Pedro Gatell mucho de ilustrado, así como Blaise Pascal, el autor de Pensées, mantuvo siempre el interés en las matemáticas y la física. Salvando (si es posible salvarlas) las enormes distancias entre los dos autores, ese mismo interés en el saber y las posibilidades de mejora que este tiene, se encuentra en el catalán. Así en sus ideas sobre educación, como las que aquí presenta en pluma del clérigo cervantino, o en las que pone en boca de Sancho para las mujeres en la historia que sobre este escribió. Insiste muchas veces además en el papel del mérito, la educación, las ciencias, aunque siempre prefiera la virtud. No es extraño en un escritor que se forma como cirujano naval en el colegio de Cádiz, luego se embarca y más tarde se quiere dedicar al saber y a la escritura. En esta época el militar deja de ser de sangre y busca la educación y el mérito, como Jorge Juan, Antonio de Ulloa o Gabriel Ciscar querían. Desde luego, la utilidad está siempre en su mira, como en la de todos los ilustrados. Sus variadas propuestas de mejora, en muy diversos temas, fueron de gran interés. 
Su formación científica y literaria (tanto en nuestra tradición, como en el clasicismo), se enlaza con muchos temas cervantinos. Así sus opiniones sobre el talante de los criados y sus reflexiones sobre la literatura, o bien acerca de la historia. Hay algunos aciertos importantes, como la presencia en sus escritos de muchos puntos de vista, pues hablan y opinan Alonso y Sancho, cura y bachiller, también el autor. O bien, la relación que señala de la comida con los cabreros con las fiestas saturnales, así como el desvío de la feliz pareja de Zaragoza para enfilar Barcelona por culpa de Avellaneda. En fin, como médico sabe bien el papel de la enfermedad en la mente del caballero, o en la de los poetas y enamorados, vieja tradición de Aristóteles o Ficino. Con frecuencia señala aspectos negativos de la corte y los cortesanos, o repudia la astrología, tal como hace con la brujería en su libro sobre la vida de Sancho. Son, sin embargo, los vicios españoles su principal objetivo, desde la inmoralidad de las costumbres, hasta la obsesión como litigantes de vecinos o vasallos. Poetas y literatura, educación de los hijos y cambio social siempre son sus temas. Muy notable es su insistencia en la defensa cervantina de la raza negra, que él amplía por su conocimiento de América.

Sin duda la obra de Cervantes es una fuente rica en opiniones morales, tal vez erasmistas, siempre católicas. Se contraponen sin embargo dos formas de ver el mundo, o más, en sus personajes. Dejemos de lado a los grandes nobles, o al morisco Ricote o a otros muchos. Sin duda el espejeo continuo y mutuo entre caballero y escudero es el principal juego social y ético de la obra. Una moral de caballería y otra de labriegos, de vasallos. Si el amo se ensueña con el pasado, el futuro está en manos del palurdo, que se convierte en Barataria y en el siglo XVIII en manos de Gatell en modelo de virtudes. En Cervantes hay un evidente interés por la educación, como es propio de la época. Preceptores, manuales, la iglesia y las órdenes como la jesuita, universidades, colegios... todo muestra por entonces el interés por formar buenos súbditos. Y también mujeres y criados, o bien buenos cortesanos y consejeros, como querían Castiglione y Huarte. Desde luego, siempre buenos hijos.

Es interesante la forma en que pretende que el libro ha sido escrito, recordando los papeles que Cervantes va encontrando sobre su famoso hidalgo. Empieza su obra narrando un viaje del autor a Madrid, tal vez desde Cádiz y pasando por la Mancha, en busca de la casa de Alonso Quijano, tal como un moro se dirige a la Meca, nos dice. Ante la falta de respuestas a sus preguntas, entra en una botica, donde el boticario también lo ignora, pues el historiador no se ha ocupado y los pueblos se lo disputan, como sucede con los grandes hombres, escribe recordando a Cervantes. Su variado apellido no facilita la localización del 
origen. Le propone el boticario un manuscrito vendido por un muchacho, remedo del cervantino (Quijote I, c. ix), que se titula la Moral de don Quixote. Basta que hable del ilustre manchego, se pronuncia, para que no sea empleado para vestir emplastos. Muestra este cambio en el destino de los papeles que el cirujano ha cedido al literato, que se ha convertido Gatell en escritor. Pagó 3 reales, que suponen el doble del costo primero, y corre a la posada, sin verse los tacones, tan grandes como está de moda. El petimetre cede también ante el ávido lector. Lee y transcribe con el mismo título estas adiciones morales, que estarían escritas por el cura. Dividida la obra por libros, recorre poco a poco las páginas de Cervantes, parándose a veces, acelerando en otras. No está de acuerdo, no concede importancia, o bien deja material para próximas obras. Quiere recoger las útiles enseñanza de Alonso Quijano el sabio y bueno, pues las del caballero de la Triste Figura «eran producciones de un delirante ciego y loco, y estas son partos de un entendimiento sano, juicioso, y lo que vale mas, escarmentado» (Gatell 1792-1793: I, sp). Hay diferencia como del día a la noche, de la verdad a la mentira, de la locura a la sensatez.

La principal obra de Gatell -aparte su notable contribución a la prensa ilustrada - son por tanto lecturas ilustradas del Quijote: si aquí la interpretación se hace por el cura, en las páginas que atribuirá a Sancho en la Vida y en la Moral es este quien la realiza. Esos diversos puntos de vista son, sin duda, lo más original de sus escritos. Presenta también opiniones valiosas sobre algunos otros personajes, así acerca del odio del bachiller tras la primera derrota, del que hablará Francisco Márquez Villanueva (Rubio 2005: 45-79, ver 71-72). La intención moralizadora y el punto de vista del clérigo marcan toda la obra y la lastran. Siempre, desde luego, está presente el arrepentimiento de Alonso Quijano, sus agrios recuerdos cargados con culpa. «iMiserable de mí! dixo luego: no se me ocurran los sucesos de la pasada vida sino para afligirme» (Gatell 1792-1793: I, 153). Nos dice, claro está, que merecen esos sucesos severa penitencia, si bien en el caso del caballero se excusan por imitar a Amadís, por seguir modelos dignos de reproducir.

Tal hacían los pintores y los artesanos prosigue, así Virgilio imitó y siguió a Homero. Sin embargo, afirma Gatell, esto no sucede en el día. Hoy solo se aprende por la práctica, no hay libros, si bien podrían traducirlos los que vierten obras sin interés. Esta pequeña crítica al saber y a las publicaciones, esa defensa de la utilidad ilustrada, acompaña a su ferviente clasicismo, su admiración tanto por la tradición grecolatina, como por la española, pidiendo seguir a los hombres grandes de la Antigüedad y de España. Ese empleo de los clásicos para moralizar e 
ilustrar está muy claramente presente en la época, así en algunos de los escritos del periodista Nipho (Peset 2010: 185-192), o en los defensores de la ciencia española (García Camarero y García Camarero 1970). Así pues, no solo se ocupará de los viejos héroes griegos o romanos, también piensa en los héroes españoles, en la historia de España. Será la tendencia que pronto retomarán Larra y Laverde, es decir la defensa de la tradición española histórica, religiosa, literaria y filosófica, coincidiendo claro está con los ilustrados. Y gracias a Menéndez Pelayo con el clasicismo humanista (Peset 2012). Si no se imita a los antiguos, sermonea Pedro Gatell, vendrán grandes peligros, cobardía, afeminación, desprecio por lo sagrado, por los padres, superiores y mayores, deslealtad, impiedad y ateísmo. La infelicidad también, dura pena para el ilustrado, dulce gozo para el romántico, en la que él ha caído.

\section{LA MUJER COMO PELIGRO}

El escritor ilustrado, entre sus comentarios literarios, ridiculizará los comienzos bucólicos con que Cervantes abría los capítulos. Así nos dice que en vez de «apenas el rubicundo Apolo habia tendido por la faz de la ancha y espaciosa tierra las doradas hebras de sus cabellos», escribirá «apenas el opaco Mercurio se hubo tendido por la faz de la angosta piel de sus cuerpos, quando no entrando, ni por los quicios de las puertas, ni ventanas, el que baña de luz el Manchego orizonte, cuarenta dias en obscuras tinieblas, denegridos los dientes, y cayéndose á puñados los cabellos, querrán lamentarse; pero no les será permitido por las gruesas, obscuras y asquerosas lenguas, y por dos rios de un licor venenoso que se despeñan de sus llagadas bocas» (Gatell 1792-1793: I, 13). Sin duda, es notable ese cambio de los pastoriles amaneceres cervantinos, ya paródicos, por esas negruras de los enfermos de sífilis tratados con mercurio. Como siempre los médicos, herederos fieles de Hipócrates, pretenden controlar la sexualidad y los matrimonios. Las obras de Tissot se difundieron y tradujeron entre nosotros, como ha mostrado Enrique Perdiguero (Porter 1992: 160-193).

Es notable la misoginia con que se enfrenta al destacado papel de la mujer en la Ilustración. Toma origen en las críticas religiosas y literarias, tanto bíblicas como medievales, pero antecede a lo que sucederá en el Romanticismo. Él arranca con otro notable pasaje cervantino, la oración que, junto a los cabreros, dedica al tiempo pasado. «Balbucientes con mil suspiros, dirán sí: dichosa edad, y siglo aquel en que no se conocia este monstruo: ó hermosas Dulcineas, señoras de estos cautivos corazones, mucho agravio nos habeis hecho en habernos puesto de esta suerte. Dichoso el que huye de vosotras, y el que evita con vosotras la menor aventura» (Gatell 1792-1793: I, 13-14). Si Ovidio recomendaba en Remedia 
amoris apartarse de las mujeres amadas, Gatell las culpabiliza del mal venéreo. Mercurio es el dios de los ladrones, del comercio (se distancia de la nueva burguesía, que había frecuentado en Cádiz), un preciado metal de los alquimistas (lejanos al sabio cirujano), pero también es el mercurio el tratamiento principal de la sífilis. Las viejas locuras del caballero, ahora se han transmutado en devaneos, familiaridad, tuteo y franqueza, pasiones, vicios y corrupción, que significan peligrosos dardos del divino Cupido en el amoroso ataque. Se culpa a las mujeres por no defender la reputación y el decoro, por su marcialidad, su peligrosa libertad.

Resultan significativas y muy contrarias las palabras de Giovanni Macchia sobre la mujer en el XVIII, siglo en que lo femenino resplandece. «Il Settecento è un secolo, più di qualsiasi altro, dominato dalle donne. La donna è il punto, dicevano i Goncourt, da cui l'epoca spande la sua luce; è la cima da cui tutto discende, è la forma sulla quale tutto si modella». Pero también señala las corrientes heredadas que inciden en los peligros de la mujer y que preceden al romanticismo. Las evidencia en Cleopatra, a través de Pascal. Sin duda hay reminiscencias de la falsa felicidad del hombre de mundo que fue Pascal y de la necesidad de dios, vertida en Pensées (Macchia 1990: 22-38, 90-96, cita en 90). Desde luego, la constante cita de los clásicos tenía peligros para la mujer. El gran Plutarco es un biógrafo de vidas de grandes hombres y su recepción en el mundo moderno con frecuencia poco favorecía a la mujer. Así Cleopatra es la maga que como Circe atonta o enfurece a los hombres, haciendo desaparecer en Marco Antonio la rectitud del soldado sencillo, del ciudadano romano. Sería la bruja (que el cristianismo demonizará), la poseedora de los trucos de amores, que sale a escena también en la vida de Sancho que escribió Gatell (Peset 2010: 233-238). Riqueza y poder, belleza y fascinación, lengua y magia se entrelazan entre los atractivos de la reina egipcia. Sin duda, la huella del clasicismo, desde Homero a Ovidio, está presente en la presentación de los peligros femeninos. Peligros que en forma de belleza y sensualidad, lujo y placeres, oratoria y bellas palabras están presentes en los miedos del autor ilustrado.

Hay un enérgico alegato en las páginas que comento contra los libros - hechos de palabras-, que son otra vez quemados, queriendo don Quijote ir incluso más allá que el cura en su inquisición. Es interesante este afán depurador en un buen estudioso y lector como Pedro Gatell. Desde luego, las razones en que se apoya al dudar de los impresos son las mismas que podrían pretender el militar Cadalso o el jesuita Vicente Requeno (Astorgano Abajo 2012) al reírse de quienes tenían (o leían) libros por moda o cursilería, por sus servicios para el 
medro o el galanteo, por devaneo o coquetería. Pero insiste Gatell más - como el jesuita- en sus nefastos contenidos, de los que ahora reniega. En especial, es el mayor peligro llenar la biblioteca de filósofos modernos, quienes hablan al corazón, con poder por los apetitos sensuales, por la persuasión de la retórica. Remite a República literaria de Diego Saavedra para ir contra esta disciplina, que como la lira de Orfeo conduce a los animales y la de Anfión mueve piedras. Sócrates — también según Saavedra - llama públicos lisonjeros a los oradores, advirtiendo del peligro de darles oficios en la república, ya que engañan a la plebe con la dulzura de sus palabras, moviendo sediciones. Si recuerda las clásicas de los Brutos, Casios, Gracos, Catones, Demóstenes, Cicerones, las iguala a las que en su época hacen Voltaire, Rousseau, Marmontel, Raynal y otros «tan detestables nombres» (Gatell 1792-1793: I, 32 y 34-35; Larriba 2003: 60). No son filósofos porque no se ocupan de la naturaleza y la moral, deshacen la sociedad, respiran corrupción, escepticismo, pirronismo. La palabra, las palabras son un peligroso y sensual atractivo, como Plutarco señalara en las amenas de la reina Cleopatra.

Esa admiración por los héroes masculinos en la historia es la misma que muestra Francisco Mariano Nipho en España, o bien Metastasio en el libreto de La clemenza di Tito en la ópera de Mozart. Para aquel además los ejemplos femeninos son negativos, mujeres reprobadas como Faustina, salvo el caso de Isocratea que acompaña a su esposo Mitrídates en la guerra. Dedica sus Varios discursos eloquentes, y politicos a la honestidad y a la duquesa de Arcos viuda (Nipho 1755). Pero incluso, como escribe Giovanni Macchia en el citado ensayo «Il naso di Cleopatra», el temido Voltaire apoya esa misma interpretación histórica que se apoya en esos grandes héroes, servidos por escasas heroínas. Sin duda, poco inventó Carlyle. También nos habla el italiano de ese respeto que se siente por Plutarco, considerado el gran modelador de héroes. Y nos recuerda su ataque a Marco Antonio y su consecuente exaltación de Octavio. Coloca el amor como fuerza frenética que contrapone a la razón y por tanto a la guerra. Antonio pierde porque se aloca y se fuga tras Cleopatra. Esta representa el mal como las mujeres de Gatell, la lengua, la palabra y la persuasión. Los libros representarían ese peligro por el engaño, por la seducción, pero también por la ambición.

«Aferrados al discurso más arcaico, escribía Mónica Bolufer, los adversarios de Feijoo mantuvieron que sólo los hombres sabían controlar sus propias pasiones, mientras que las mujeres, lascivas, trataban de subyugarlos con la aparente inocencia de su hermosura, fachada engañosa de una naturaleza perversa. La "deshonestidad" femenina que en su tiempo fustigaban moralistas y escritores satíricos no era, a sus ojos, sino una prueba de la malignidad de las 
mujeres» (Bolufer 1998: 52). Ante esa nueva mujer, nos dice Gatell, en el día falta la corrección por los padres, a diferencia de aquella admirada educación por el tío y la consecuente prudencia de Marcela en la novela cervantina. Teme los paseos (así, por la Puerta del Sol) y las funciones públicas, advierte del peligro de las jóvenes de 15 años. Más tarde, también peligran otras mujeres, que deben recibir continuas visitas y cortejos por la categoría de sus padres. Sin remedio se difunden la belleza, las virtudes y la riqueza, así las de la pastora Marcela. Se muestra moderno, pues alaba la actitud del tío, en no retenerla por la dote y consultar su voluntad, ofreciéndole las propuestas de casamiento, no obligándola a tomar estado. Es la nueva defensa de la voluntad de la mujer, presente en El sí de las niñas de Leandro Fernández de Moratín, o bien en las óperas mozartianas. El padre que obliga tiene las entrañas de una fiera, de un tigre. La prudente negativa de Marcela contrasta con la precipitación actual de las jóvenes por casarse y librarse de la opresión de los padres. Nada saben hacer, presumía una madre. No las enseñan para que no sean criadas, «bueno seria que la hubiese instruido para servir á unos calzones». Las madres las quieren ociosas, sin labores, leyendo comedias, ignorando el orden y gobierno de una casa, de una familia y «los oficios propios de una muger acerca de su marido» (Gatell 1793-1793: I, 108109).

Otras veces, los padres se precipitan. Más que por hermosura, la elección se debe hacer por la honra y las virtudes. «Una fea virtuosa es preferida siempre á una hermosa sin la virtud». Su admiración y fidelidad por Cervantes le hacen admirar el papel de Marcela. «Yo nací libre», recuerda. «No me llame cruel ni homicida...», también transcribe (Gatell 1792-1793: 129-131). Sin embargo, el Gatell conservador recupera su papel y concluye que la mujer, después de consultar con una misma y con sujetos prudentes, debe dejar la respuesta a los padres. «Fuera aquel abuso de tratar el casamiento las niñas, dar palabra, y aun lo que es peor, firmar con sangre que aun en el caso de no conformarse los padres lo han de verificar». Se suponen las consecuencias. Una se considera loca por ligarse tan joven, otra por la prisa de la madre en casarla, alguna por no hacer caso de los consejos sobre un mal partido, otras por casarse sin meditar, consultar o atender a los padres. Pensad «que una vez empeñadas no os queda mas lugar que para padecer, sufrir y callar» (Gatell 1792-1793: I, 132 y 136). Un mal matrimonio lleva a peleas, divorcios y celibatos.

\section{ENAMORADOS Y POETAS}

Prosigue sin piedad, claro está, clamando contra los peligros del amor, esa pasión que atacó al «furioso Cardenio». Nos recuerda «la reconvencion al 
parecer justa del Escudero de que Cardenio era loco». En cuanto a Alonso, en su imitación de Amadís y Roldán, si estos según Sancho tuvieron causa, no la tuvo él cuando afirma que será loco hasta recibir la respuesta de Dulcinea. Su tardío enamoramiento muestra esa «manía de enamorado». Nos relata casos de obsesiones, un viejo enamorado de una joven, o un rico entusiasmado por una mina de poca calidad, en que pierde la riqueza que amasó por años. Nos trae el cirujano la elegante poesía de Cardenio, en que afirma que en el duelo, la muerte, la mudanza y la locura son remedios de la pasión. «Son tres simples que sin haber venido de Arabia, de las Indias, ni del Mogol, curan como específicos el mal de amor» (Gatell 1792-1793: I, 145, 148, 180 y 184-185). Es, sin duda, otra crítica del cirujano ilustrado ante los caros e inútiles remedios heredados de la farmacopea galénica y traídos desde lejanas tierras. Era época de renovación médica, en la que se buscaban remedios simples, naturales y eficaces.

El cura se lamenta de la edad de Alonso, pero según Gatell no conocía los amores viejos de César con Cleopatra, y otros muchos que cita él mostrando su erudición. Nadie resiste al amor: el sabio y el valiente, el héroe, el encopetado, todos sucumben... solo resistieron Carlos XII e Isabel de Inglaterra, nos dice. Recuerda ejemplos de los médicos clásicos, que salvaron a príncipes de los males de la pasión. «Imperios, Reynos enteros se han visto desbaratados por los monstruosos efectos del amor» (Gatell 1792-1793: I, cita 191, ver 187-189). Para Aristóteles es un olvido de la razón cercano a la locura. Ovidio señala en el Arte de amar que puede matar, también un santo padre; Séneca lo considera fuerte como la muerte, siempre victoriosa; para Diógenes es propio de hombres holgazanes y vagabundos. Así ese Quijote y sus descendientes. Humilla a los héroes, como sucedió con Aquiles, Hércules, Sansón... Cree todo don Quijote de su amada, por eso Heliodoro afirma que el pensamiento del enamorado es como el de un hombre bebido, pues nadan en la pasión. La sexualidad y la bebida se imbrican desde antiguo. Son esclavos, como dijo Propercio.

Los poetas no dicen la verdad sobre las amadas, como falsamente se señaló en Petrarca. Insiste en esa larga tradición, la del poeta y el amor. «Una de las gracias mas especiales de amor es el hacer poetas, el inflamarlos y electrizarlos. [...] En efecto los mejores poetas han trabajado las piezas mas especiales tocante á asuntos de amor, especialmente aquellas en que expresan sus penas» (Gatell 1792-1793: I, 194). Desde luego, entre muchos, están Petrarca, Alceo, Virgilio, Catulo, Ovidio, Propercio, Tibulo, Dante, además de los Herreras, Villenas, Santillanas, Menas, Rodrigos, Mendozas, Boscanes, Garcilasos, Camoens, Cervantes, Quevedos, Calderones y otros. Acumula como desdichados ejemplos de sus 
consecuencias, en eruditas citas, casos clásicos de amores con animales u objetos, de apasionados amantes que cometen asesinatos en la propia familia. Quijano imita a Amadís furioso, sandio, desesperado, a Roldán cuando se volvió loco. Los jóvenes faltan al respeto y al amor a los padres, son infelices, pierden la carrera. Los padres no separan a los hijos de la ocasión y las compañías, luego ellos mismos sufrirán disgustos y castigos. Y si el amor por Dulcinea era casto, en el día solo hay corrupción, son jóvenes. El amor lleva castigo y pena, disgustos y pesares. Así el dominio por los sarracenos, por culpa de don Rodrigo. Recuerda también las caídas del rey David. Los peligros en la charla, los placeres, el amor carnal, llevan a la ruina de las familias, a las enfermedades... contrasta siempre con el amor puro, el ejemplo moral de Alonso Quijano, Cardenio, o bien Petrarca.

Aunque el amor no respeta clases, condiciones, razones ni barreras, pues «tiene la misma condicion que la muerte», entiende Pedro Gatell que Sancho no comprendiera el amor de Altisidora. Hay caballeros que con ser mirados por una dama ya se creen queridos, nos dice. Respuesta digna de Sócrates es la de Alonso a Sancho, la belleza del alma es superior a la del cuerpo. Si se reúnen las dos bellezas, las dos almas, será un ave fénix. Ese animal prodigioso que, en el mismo sentido, trae Lorenzo da Ponte en alguna ópera mozartiana. Pero no sucede así, se entusiasman de engañosas imágenes, como las de Zeuxis, Apeles, Rafael o Murillo. «¿Quántos se hallan burlados, pues creidos de encontrar una muger hermosa, se acuestan con un angel y amanecen con un arpía» (Gatell 1792-1793: II, 259 y 262). Si la belleza desaparece por enfermedad, se debe buscar el entendimiento, la honestidad, la buena conducta e igual educación, quien sepa gobernar la casa, regir la familia y cuidar del esposo, no perseguir las gracias, saber engalanarse, bailar, representar, tañer una guitarra. La mujer debe buscar un hombre de bien y trabajador.

El cura y el bachiller Gatell no dejan de moralizar las desgracias de Dorotea en la novela cervantina, peligrosas para las mujeres, sobre todo jóvenes, que son engañadas tal como logró don Fernando. Como los hombres, «las mugeres están expuestas á la misma miseria, y en alguna manera mucho mas, por su debilidad y por la facilidad natural que tienen en creer á los hombres, que en iguales casos no dexan piedra que tocar, artificio de que valerse, ni voces con que ablandar el corazon aun mas empedernido y duro que el de la hermosa Dorotea». No puede el cura absolverla «del delirio que cometió», pues no hay que ofender a dios. Si obró fundada en que algunas mujeres humildes habían hecho fortuna, debía advertir que los hombres son falsos y malos, y tras satisfacer la pasión pasan al desprecio y al odio. Hasta acá la reflexión del cura licenciado, ahora el bachiller 
apostilla: «es forzoso creer que en las batallas de amor han perecido mas mugeres que hombres». Muchas son las que recuerda, Dido, Cleopatra, o bien Sofonisbe; si entonces sin duda se trataba de un amor sensual, hoy todavía es peor, nos insiste. «Esta enfermedad no tiene otros remedios que los que señalan los Médicos para la peste» (Gatell I, citas en 208, 209, 212 y 215). Huir es necesario, no fiar ni de criada ni de amiga. Recuerda una vez más a Petrarca y la descripción del amor como niño triunfante con sus flechas. Hijo del ocio y la lascivia, se alimenta de dulces y agradables pensamientos. Los acordes de Cosi fan tutte resonaban por toda Europa.

Tras los cervantinos elogios a Basilio, insiste Sancho en las bodas de Camacho en los deberes del matrimonio. Este debe ser entre semejantes, de nuevo se recuerda así la conveniente elección por el padre, que debe casar a las hijas con iguales y no con criados. Añade ahora Gatell como demostración un soneto de Lupercio Leonardo de Argensola. Don Quijote también aprecia en la mujer más la fama que la hacienda; pero aquella frágil es, como el vidrio, la burbuja de jabón, el espejo... Hay que cuidar el buen nombre, la buena opinión, pero hay que añadir la apariencia como siempre, que se obtiene por la virtud, la sinceridad, el vestido, evitando con rigor la marcialidad, el poco recato, la libertad, el trato familiar. Adoctrinen los padres a los hijos, los maridos a sus mujeres. Se ha perdido el recato de la española antigua. «¿Quándo veremos renacer aquella modestia, aquel pudor que les venia al rostro en el momento que oian ó veian alguna palabra, alguna accion descompasada» (Gatell 1792-1793: II, 111-112). Más respetada es la virtuosa, aunque sea pobre. Y no hay que olvidar la maldad de los hombres. Es el juego constante en Cosi fan tutte. Esos soldados - en la pluma de Lorenzo Da Ponte- que respetan el honor, pero lo ponen a prueba, con mil añagazas, previstas y apoyadas por filósofos escépticos y criadas inmorales. Como siempre hizo el caballero andante, hay que defender el honor de las mujeres, no aceptar que sean criticadas, como ocurre en las tertulias. Contra la crítica citará de nuevo ejemplos clásicos, a Eurípides, Plutarco, Erasmo...

Hay que defenderlas de los ataques que consideran brujas a las mujeres, tal como ilustrará en la vida de Sancho. Comenta ahora las palabras de don Quijote sobre las prácticas «que tanto se usan en España; que no hay mugercilla, page, ni zapatero de viejo que no presuma de no alzar una figura, como si fuera una sota de naipes del suelo, echando á perder con sus mentiras é ignorancias la verdad maravillosa de la ciencia» (Gatell 1792-1793: II, 135, ver 1). Hoy por conocimiento y por religión nada de esto se cree. Hay que señalar aquí al ilustrado que defiende la verdadera ciencia, al cirujano que conoce la medicina, 
pero también al católico que amenaza con la severidad de la iglesia. También al misógino que señala a la mujer, que une con oficios que él considera viles. Es el mismo que mostró una bruja en la aldea en la vida del escudero, en cuyo castigo, si bien suave, concurren el alcalde Sancho y como siempre el cura. La razón ilustrada ya no cree en estas invenciones. Pero ha sido llamado por uno de esos «hombres de talento», quien le pregunta y se angustia por si le han hecho algún mal. Lo atribuye a una señorita que lo amaba y lo vio con otra: lo amenaza y se siente mal, los médicos no conocen la enfermedad. Con risas, se despide el autor dejando «al tal Literato moderno encendido en cólera». Nada sirven, afirma, las «malhechorías de esta naturaleza», al igual que no hay agoreros ni zahoríes (Gatell 1792-1793: II, 254, 255 y 258). Tampoco, por tanto, el hechizo maligno de la mujer y de las brujas. Se desacredita el que se considera escéptico, quien pedirá a un cura que le diga un evangelio, que ambos estiman buen remedio.

\section{COSTUMBRES Y LIBERTADES}

«Para el ilustrado español, los placeres del gusto, al margen de los que las operaciones de la razón suscitan en el entendimiento, son materia sospechosa sobre la que aplicar un riguroso examen» (Hontanilla 2010: 321). Así, las costumbres se han relajado según afirma Gatell, en el siglo y entre los cortesanos. La duquesa cervantina no quiere que la desmonte Alonso, solo el duque, mientras en el día cualquiera toma a la mujer en sus brazos. Estos pasajes recuerdan con facilidad los ejemplos morales del jesuita Vicente Requeno. «Salen á un paseo marido y muger con algun amigo: este ha de ser el que le ha de dar la mano y el brazo; y aquel ha de hacer el oficio de page ó lacayo. Salen al campo, y para montar no ha de ser el marido quien la ha de subir al aballo, quien le dé la mano para subir al coche, sino el camarada, el extraño». Ni cristiano, ni español antiguo es este proceder. Las antiguas costumbres, tan recatadas, se tildan de poco atentas, nada marciales y sin crianza. Trastornado el imperio español, «hemos degenerado» (Gatell 1792-1793: II, 168-169). Se ha visto el destierro de las buenas costumbres, ahora son malas y con corrupción, son pésimo ejemplo de las madres a las hijas, suponen deshonor, incendio y perdición. Pueden sin duda conducir a la ruina de los matrimonios. Preferir al marido se debe, ser cristianas y no modistas, españolas y no extranjeras.

Sancho llama vieja a la dueña Rodríguez y esta se enfada. Aun más en estos tiempos, con esas malas costumbres, las mujeres ocultan la edad, las canas y las arrugas. Las mayores se empolvan, usan afeites, nuevas modas, quieren ser tratadas como muchachas, se declaran incluso. Una rompe un espejo al ver las legañas y los hoyos por falta de dentadura. Son «locas, fatuas y mentecatas». 
Igual sucede con los hombres; siempre afeminados, se tiñen las canas, usan unturas, se afeitan. «Locura, y grande es en las Señoras ancianas, ó que caminan para ello; pero lo es mucho mayor en los hombres. Una prueba constante de no haber jamas tenido juicio es pretender ocultar los años. Pretenden obscurecer lo mismo que debian procurar ostentar para manifestar madurez, y para ser respetados y venerados. Las canas, las arrugas, jamas inducen imperfeccion». Son muy necesarios la virtud y el juicio. Se apoya una vez más en un clásico, ahora en un epigrama de Marcial. No se deja desnudar Alonso Quijano por las damas, es necesaria la honestidad. Hoy se desnudan, las visitas son «teatros de lascivia» (Gatell II, 1792-1793: 175-176 y 180), lujuria en las conversaciones y peligroso cortejo.

Los personajes dignos, los gobernadores, si son solteros deben vivir castos y con prudencia; si son casados, tener cuidado, porque las mujeres son compasivas y se dejan persuadir. Además, apartando a sus maridos de la justicia, los hacen codiciosos. Si enviuda y mejora con el nuevo matrimonio, ha de evitar ambición, medro e injusticia. Debe atender al pobre (pero tener cuidado con sus lágrimas y malicia) más que al rico (que influye con dádivas y promesas). También actuar con misericordia, olvidar las injurias de los enemigos al juzgarlos, pues la pasión ciega. Debe también el juez tener cuidado con las mujeres hermosas, con sus súplicas, lágrimas y suspiros, «no sea que le alucine la pasion» (Gatell 17921793: II, 212). Si él piensa al parecer en Circe, no hay que olvidar a Friné, quien convenció a su tribunal mostrando su hermosura.

Este timorato cirujano no nos debe hacer olvidar una importante tradición en elogio de las mujeres, que él mismo conocía sin duda. No podemos pasar por alto que en el mismo Plutarco hay apasionadas defensas de las mujeres. Recordemos la vida de Coriolano, en la que el papel de la madre y la esposa en defensa de la paz es digno, heroico y elegante. Apoyan a la patria ofreciendo en teatrales gestos su cuerpo y su dignidad, su vida y su familia y saliendo victoriosas, alabadas por el pueblo, los poderosos y los dioses. Esa misma teatralidad llevará esta pieza a la escena con William Shakespeare, a la pantalla con Ralph Fiennes. No olvidemos tampoco el papel también pacifista que en el teatro representan las mujeres en Lisístrata de Aristófanes. Y, en fin, con motivo del último centenario de las aventuras del caballero, hoy tras Concha Espina o María Zambrano, Carmen Castro o Lidia Falcón, renuevan A. Bernárdez Rodal y J. Vázquez Marín —entre abundantes especialistas- ese carácter ilustrado de las mujeres cervantinas (Rubio 2005: 283-304 y 481-517). Se entiende este calificativo como búsqueda de la libertad, incluida la amorosa y sexual, también el saber leer y escribir, ser 
letradas (Hernández Sandoica 2012). Triste sino el de las páginas y las heroínas de Miguel de Cervantes, ahora convertidas en abrumadora moral en la pluma del cirujano ilustrado Pedro Gatell. Y, sin embargo, este conocía bien y cita algunas alabanzas de Plutarco a las mujeres (Larriba 2003: 66).

\section{REFERENCIAS BIBLIOGRÁFICAS}

ÁLVAReZ BARRIENTOS, Joaquín (1991): La Novela del Siglo XVIII, en R. de la Fuente, ed., Historia de la literatura española, 28, Madrid-Gijón, Júcar.

- (2006): Los hombres de letras en la España del siglo XVIII. Apóstoles y arribistas, Madrid, Castalia.

Astorgano Abajo, Antonio (coord.) (2012): Vicente Requeno (1743-1811). Jesuita y restaurador del mundo grecolatino, Zaragoza, Universidad de Zaragoza.

BOlufer, Mónica (1998): Mujeres e Ilustración. La construcción de la feminidad en la España del siglo XVIII, Valencia, Institució Alfons el Magnànim.

CARNERO, Guillermo (2009): Estudios sobre narrativa y otros temas dieciochescos, Salamanca, Universidad de Salamanca-Prensas Universitarias de Zaragoza.

Flores, R. M. (1982): Sancho Panza Through Three Hundred Seventy-five Years of Continuations, Imitations, and Criticism, 1605-1980, Newark-Delaware, Juan de la Cuesta-Hispanic Monographs.

García Camarero, Ernesto y Enrique García Camarero (1970): La polémica de la ciencia española, Madrid, Alianza Editorial.

Gatell, Pedro (1792-1793): La moral de don Quijote, deducida de la historia que de sus gloriosas hazañas escribió Cide-Hamete Benengelí. Por su grande amigo el cura. Dala á luz el Br. D. P. Gatell, 2 vols, Madrid, Imprenta de González.

- (2010): La moral del mas famoso escudero Sancho Panza (1793), Mairena del Aljarafe, Sevilla, Extramuros Edición.

GUTIÉRREZ CUADRADO, Juan (2005): «Arcaísmos y otros “-ismos": la selección léxica en el Quijote», Boletín de la Real Academia Española, LXXXV, pp. 335-374.

Hernández SANDOICA, Elena (ed.) (2012): Política y escritura de mujeres, Madrid, Abada Editores.

HonTANilla, Ana (2010): El gusto de la razón. Debates de arte y moral en el siglo XVIII español, Madrid-Frankfurt am Main, Iberoamericana-Vervuert Verlag.

Larriba, Elisabel (ed. e int.) (2003): El Argonauta español. Periódico gaditano por el bachiller D. P. Gatell, Cádiz, Universidad de Cádiz.

- (2005): De la lancette à la plume: Pedro Pablo Gatell y Carnicer. Un chirurgien de la Marine Royale dans l'Espagne des Lumières, Aix-en Provence, Publications de l'Université de Provence.

MACCHIA, Giovanni (1990): Elogio della luce. Incontri fra le arti, Milano, Adelphi Edizioni.

NIPHO, Francisco Mariano (1755): Varios discursos eloquentes, y politicos, sobre las acciones mas heroycas de diferentes personages antiguos, o modernos, en los que, por medio de prudentes avisos, puede lograr el hombre el verdadero modo de gobernarse, segun los 
preceptos de las tres partes constitutivas de la sabiduria humana: es a saber, Ethica, Politica, y Economìa. Hará este epilogo D...., Madrid, En la Oficina de D. Gabriel Ramírez.

Ovidio (2011): Remedios contra el amor, traducción Francisco Socas, Madrid, La Esfera de los Libros.

PÉREZ MARTínEZ, Ángel (2012): El Quijote y su idea de virtud, Madrid, CSIC.

PESET, José Luis (2010): Las melancolías de Sancho. Humores y pasiones entre Huarte y Pinel, Madrid, AEN.

- (2012): «Sobre ciencias e inquisiciones», Ínsula. Revista de letras y ciencias humanas, 790, pp. 11-14.

Plutarco (1977): Vies XIII. Démétrios-Antoine, traducido por Robert Flacelière y Émile Chambry, Paris, Société d'Édition «Les Belles Lettres».

PORTER, Roy, ed. (1992): The Popularization of Medicine 1650-1850, London and New York, Routledge.

PRAZ, Mario (1999): La carne, la muerte y el diablo en la literatura romántica, traducción Rubén Mettini, Barcelona, El Acantilado.

RubIO, Fanny, ed. (2005): El Quijote en clave de mujer/es, Madrid, Instituto de Investigaciones Feministas, Editorial Complutense. 